\title{
Niñas migrantes: relatos de menores mexicanas repatriadas de Estados Unidos
}

\section{Teenage migrant women: stories of Mexican minors repatriated from United States}

\author{
Oscar Misael Hernández-Hernández \\ Colegio de la Frontera Norte, México. \\ ohernandez@colef.mx \\ Recibido: 10-1-2015 \\ Aceptado: 03-2-2015
}

Resumen

Hasta hace unos años la migración indocumentada de menores mexicanos a los Estados Unidos ha sido vista como un fenómeno importante, pero poco se sabe de sus experiencias migratorias diferenciadas por sexo. Por lo anterior, el objetivo del presente trabajo es presentar y analizar los relatos de dos niñas migrantes, una oriunda de Chiapas y otra de Oaxaca, quienes fueron detenidas por la Patrulla Fronteriza al cruzar la frontera México-Estados Unidos y repatriadas por las ciudades de Brownsville, Texas y Matamoros, Tamaulipas. Se argumenta que sus narrativas permiten comprender cómo algunas menores mexicanas viven el proceso migratorio, así como la utilidad del relato de vida como técnica para captarlo.

Palabras clave: México, migración, niñas, relatos, repatriación.

\begin{abstract}
Undocumented migration of Mexican minors to the United States is a phenomenon that has already deserved a good amount of research, but still little is known about their migration experiences differentiated by sex. Therefore, the objective of this paper is to present and analyze the stories of two teenage migrant women: one from Chiapas and the other from Oaxaca, who were arrested by the Border Patrol while crossing the border between Mexico-United States and repatriated from Brownsville, Texas to Matamoros, Tamaulipas. It is argued that their narratives provide an insight about how some Mexican teenage migrant women live the migration process, and the usefulness of the life story as a technique to capture it.
\end{abstract}

Key words: México, Migration, Teenagers, Stories, Repatriation.

Sumario

1. Introducción | 2. Estrategia metodológica | 3. Niñas, familia y motivaciones para migrar | 4. Niñas y redes sociales de apoyo migratorio | 5. Niñas y viaje a la frontera norte de México | 6. Niñas y emociones en el viaje migratorio | 7. Conclusiones | Referencias bibliográficas

\section{Cómo citar este artículo}

Hernández-Hernández, O. S. (2015): "Niñas migrantes: relatos de menores mexicanas repatriadas de Estados Unidos", methaodos.revista de ciencias sociales, 3 (1): 122-133. http://dx.doi.org/10.17502/m.rcs.v3i1.76 


\section{Introducción}

La migración indocumentada de menores de edad mexicanos a los Estados Unidos es un tema que hasta hace poco ha adquirido importancia. Tal como afirma Mancillas Bazán (2009: 211-212), esto se debió a que era considerada poco significativa e intrascendente comparada con la abrumadora participación de adultos en la migración transnacional, lo que propició su invisibilidad analítica. Por otro lado, como han observado Chavez y Menjívar (2010: 76), este fenómeno vivió un proceso similar al de la migración de mujeres: su estudio fue relegado y sólo recientemente "los especialistas están recuperando los relatos y experiencias de los niños que también habían sido silenciados", empezándose a concebir a los menores migrantes como actores sociales.

Sin embargo, a pesar de que en los últimos años ha habido un número considerable de estudios sobre el tema (Hernández Sánchez, 2008; Silva Quiroz, 2010; Valdés Gardea, 2008 y 2011; entre otros), la mayoría de estos abordan la migración de menores sin hacer una diferenciación por sexo de sus experiencias y trayectorias, o bien, centrándose únicamente en los niños. Es indudable que al igual que en la migración transnacional de adultos, donde predominan los flujos de hombres y no de mujeres, en la migración transnacional de menores participan más niños que niñas. Por ejemplo, en el 2010 se registraron un total de 20.438 "eventos" de menores mexicanos repatriados desde Estados Unidos, de los cuales el 19,0\% eran mujeres (Centro de Estudios Migratorios, 2010). Para el año 2011 fueron repatriados 15.524 menores, siendo mujeres un 17,2\% (Centro de Estudios Migratorios, 2011); mientras que de enero a julio del 2012 se reportaron 10.697 repatriaciones, representando las mujeres el 15,6\% (Centro de Estudios Migratorios, 2012). Como se observa, el porcentaje de niñas migrantes repatriadas es menor que el de niños y disminuye.

Aunque los datos presentados hacen referencia a una cantidad considerable de niñas, es mucho menor que la de niños. Además, dichas estadísticas aluden a "eventos", es decir a la posibilidad de que una misma persona migrante haya sido repatriada en más de una ocasión. En otras palabras, puede haber una sub-representación de la migración y repatriación transnacional de niñas. Las estadísticas oficiales sobre niñas mexicanas migrantes repatriadas de Estados Unidos, además, no sólo muestran que constituyen un porcentaje menor comparado con el de niños en la misma condición, sino también que oscilan entre los 0 y los 17 años, y que aquellas situadas en el rango de los 0 a los 11 años de edad, en su mayoría eran acompañadas y una minoría no lo eran. En otras palabras, a priori las niñas migrantes se encuentran en una situación de extrema vulnerabilidad en tanto mujeres, menores de edad, poco acompañamiento, además de los riesgos "naturales" que implica viajar y cruzar la frontera de forma clandestina. Sin embargo, poco o nada se sabe acerca de esta situación y de las experiencias migratorias de las niñas.

Por lo anterior, el objetivo de este trabajo es hacer una primera aproximación cualitativa a la migración indocumentada de niñas mexicanas. Específicamente analizaré los relatos migratorios de niñas oriundas de algunos estados del sur del país, que cruzaron el río Bravo y que fueron repatriadas de los Estados Unidos por la frontera entre Matamoros, Tamaulipas y Brownsville, Texas, al noreste de México. Aquí me baso en un trabajo de campo sobre menores migrantes repatriados, de ambos sexos, realizado entre marzo y junio del 2012 en el Centro de Atención al Menor Fronterizo (CAMEF) ubicado en la ciudad de Matamoros, el cual funge como albergue temporal de menores migrantes repatriados -mexicanos y centroamericanos- desde los años noventa (Quintero Ramírez, 2007). El CAMEF, al igual que otros albergues instalados en ciudades de la frontera norte de México, fue creado a razón de un convenio internacional en favor de la niñez migrante, pero también porque desde la década de los ochenta la ciudad de Matamoros ha sido un corredor migratorio importante para centroamericanos que van a la costa este de Estados Unidos (Sánchez Munguía, 1993).

No obstante, en décadas posteriores la ciudad de Matamoros también pasó a ser un corredor migratorio relevante para connacionales. A pesar del aumento de la vigilancia de la frontera de Estados Unidos por esta ciudad y las recesiones económicas locales (Quintero Ramírez, 2011), el tránsito y la repatriación migratoria ha sido constante, tanto de adultos como de menores. En este contexto se ha dado la repatriación de menores migrantes mexicanos, quienes provienen de diferentes estados de la república y se dirigían a distintas ciudades de los Estados Unidos. Como lo reflejan las estadísticas nacionales, por la ciudad de Matamoros son mayormente niños que niñas los repatriados. Hasta noviembre del 2011, por ejemplo, se reportaron un total de 362 menores albergados en el CAMEF, de los cuales un 25\% eran niñas (CAMEF, 2012). 
Durante la temporalidad del trabajo de campo, solamente logré contactar a seis niñas que fueron repatriadas e ingresadas en el CAMEF. Ellas fueron entrevistadas una sola vez dada la fugacidad de su estancia, pues en este tipo de albergues institucionales, se apoya a los menores migrantes repatriados contactando a sus familiares, quienes van a recogerlos -o envían a alguien- lo más pronto posible. Como se mostrará, a través de los relatos de las niñas es posible captar al menos cinco dimensiones: la estructura familiar, las motivaciones para migrar, las redes sociales, el viaje migratorio y la construcción de emociones antes y después de cruzar la frontera. Se trata de dimensiones que permiten adentrarse en sus cortas vidas, pero sobre todo, en sus experiencias como migrantes indocumentadas.

\section{Estrategia metodológica}

En este trabajo presento los relatos migratorios de dos de las seis niñas entrevistadas: una oriunda de Chiapas (Gloria) y otra de Oaxaca (Carolina), ambos estados situados al sureste de México. Se eligieron estos dos casos porque, por un lado, en cierta forma "representan" a las otras dado que provenían de las mismas entidades, y por otro, porque sus narrativas constituyen una riqueza fenomenológica para comprender parte de la migración femenina de menores. Al momento de las entrevistas las niñas migrantes tenían 14 y 15 años de edad, respectivamente, y cada una tenían estudios de secundaria y bachillerato inconclusos. Ambas se caracterizaron por llegar a la frontera norte de Tamaulipas para intentar cruzar acompañadas a ciudades del este de los Estados Unidos, formando parte de una corriente migratoria del sur de México (Ávila Sánchez, 2007). Con Gloria y Carolina, al igual que con los niños migrantes repatriados por Matamoros, utilicé un guión de entrevista que permitió captar sus experiencias desde que iniciaron el viaje migratorio en sus lugares de origen, hasta que fueron detenidas y repatriadas por agentes de la Patrulla Fronteriza de los Estados Unidos, logrando identificar diferentes eventos que vivieron, a la vez que interpretaron.

Apropié la técnica del relato de vida para reconstruir los relatos migratorios de las niñas repatriadas. Basado en Bertaux (2005:36), considero la técnica como una forma narrativa que inicia "desde el momento en que un sujeto cuenta a otra persona, investigador o no, un episodio cualquiera de su experiencia vivida", destacándose significados pero también referentes en tanto relaciones, procesos y normas. Con base en lo anterior, las entrevistas a las niñas fueron concebidas como un medio para conocer $-\mathrm{y}$ reconstruir- sus relatos migratorios. Si bien se cuestiona que "la intervención del transcriptor" deviene en la "ficcionalización" de los hechos (Randall, 1992), he rescrito las narrativas de las niñas en las entrevistas y las presento en primera persona como relato para de esta manera poder "captar la realidad subjetiva -lo vivido subjetivamente-" (Rojas, 2008:86). El relato de vida, entonces, me fue útil como recurso para reconstruir sólo algunas de las experiencias de las niñas migrantes repatriadas, pues como hace tiempo aclaró Durand $(1996: 13)$ en un trabajo similar, "Se trata de reconstruir la historia migratoria, que no de vida (...)". En este sentido, dicha estrategia metodológica es viable para acercarse a la migración indocumentada de menores.

La forma en que abordo los relatos migratorios de las niñas en cuestión, intenta abarcar las funciones que tiene el relato de vida en sí: una exploratoria, otra analítica y una más expresiva (Bertaux, 2001), es decir, adentrar en un campo de estudio a partir de narrativas experienciales, hacer un análisis de significados y referentes estructurales, y socializar los hallazgos. Claro que, como señala Bertaux (2001), un relato siempre será utilizado, leído y contextualizado de formas diferentes. No se trata de una excusa, sino más bien de una precisión para comprender que al menos en esta fase, el análisis y la reflexión de los relatos de Gloria y Carolina intentan desentrañar algunos indicios -más no pruebas- de la migración femenina de menores de edad. Para finalizar, deseo matizar que si bien dentro de la literatura sobre la migración de menores mexicanos prevalecen diferentes "tipologías" de éstos (Mancillas Bazán, 2009), e incluso el término "menor" se presta a diferentes interpretaciones, a lo largo de este trabajo me referiré a las niñas migrantes y a la migración femenina de menores como sinónimos y casos específicos. 


\section{Niñas, familia y motivaciones para migrar}

Tal como han afirmado Ariza y de Oliveira (2001:22), "Las migraciones internacionales han complejizado aún más los arreglos y las relaciones familiares. Los procesos de transnacionalidad han contribuido a dispersar tanto los hogares como los lazos familiares". Para estas autoras, además, el impacto de la migración en la familia varía dependiendo del tipo de movimiento.

Desde una perspectiva psicosocial (Estrada Inda, 2007), los casos presentados muestran que las niñas migrantes provienen, por un lado, de una familia estructurada, y por otro, de una familia desestructurada; ambas caracterizadas por un sistema familiar cuyo ciclo vital ha sido reorganizado tanto por procesos socioeconómicos regionales como por experiencias migratorias transnacionales.

Tengo 14 años, soy de México, Chiapas, de un pueblo que se llama Cacahuatán. Ahí vive toda mi familia y ahí estudiaba la secundaria, el primer año. Mis papás trabajan, pero no sé en qué, salían a trabajar pero no sabía a dónde trabajaban, es que yo salía a estudiar, salía y ellos trabajaban hasta tarde o noche. Tengo una hermana, tiene 25 años y también vive en Chiapas. Me agarraron el lunes, cruzando el río para pasar, para cruzar McAllen, si. Me vine con un cuñado, el novio de mi hermana, se iban a casar. Nomás nosotros nos venimos, mi hermana se quedó. Acá me iba a venir con una tía, con una tía que me iba a recoger allá en Chicago. A nosotros nos recogían de ahí y nos iban a dejar en la casa, nos iban a recoger para llevarnos a Houston (Gloria).

Tengo 15 años, soy del estado de Oaxaca, el municipio es Santa María Zacatepec, y el pueblo se llama San Vicente Piñas. Estoy soltera y allá en Oaxaca estudiaba, iba en el segundo grado de telesecundaria. Allá (en Oaxaca) vivo con mis abuelos. Tengo papás y hermanos más grandes: un hermano y tres hermanas, yo soy la más chica; pero mi mamá y mis hermanos están en Estados Unidos. Y ya mi papá está en Oaxaca, pero él se separó de mi mamá y tiene otra mujer, se separó hace no sé cuántos años. Mi hermano el grande tiene como los 23 creo, y mi hermana la mayor 22, parece. Hace como 6 años, me parece, que se fue mi familia (a Estados Unidos). Allá están en Nueva York. Mi mamá se fue sola, no se llevó a mis hermanos. Bueno, mis dos hermanos, la más grande y el hermano, ya estaban allá. Es que en una ocasión ya estábamos todos allá, pero venimos porque tres, bueno dos hermanas y yo nos venimos y mi mamá, porque lo habían agarrado a mi papá, la policía (Carolina).

Sin duda, las crisis nacionales en México han impactado las vidas de innumerables personas y han incidido en la reorganización familiar, principalmente al orillarlas a migrar a los Estados Unidos como alternativa de sobrevivencia (Medina Núñez, 1996). Tal es el caso de varias familias de comunidades rurales -mestizas e indígenas- del sureste del país. Jáuregui Díaz y Ávila Sánchez (2007), así como Alvarado Juárez (2008), por ejemplo, señalan que como resultado de la firma del Tratado de Libre Comercio, los conflictos armados y la depreciación de cultivos, en las últimas décadas se ha vivido una migración tanto nacional como internacional por parte de familias de Chiapas y de Oaxaca, respectivamente. Los relatos de Gloria y Carolina sobre sus familias bien pueden situarse en este escenario regional y nacional de crisis socioeconómicas y políticas, pero además hay que reconocer que al menos en México no sólo las familias transnacionales, sino también la migración de menores de edad, es un fenómeno histórico y evidente después del movimiento armado (Hernández Sánchez, 2008).

Por supuesto, la estructura y organización familiares de ambas menores, hay que situarlas en el escenario de vidas transnacionales más acentuadas en la modernidad y con impactos en la reconstrucción de identidades (Gledhill, 2009), donde los proyectos personales se articulan con decisiones familiares y oportunidades socioculturales allende las fronteras nacionales. Al menos en el caso de Gloria, es evidente que migrar no fue un proyecto personal sino familiar, pues eran sus padres quienes deseaban y decidieron que se fuera a continuar sus estudios de High School en Chicago, aprovechando las redes sociales de tíos, tías y primos de Chiapas que ya residían en aquella ciudad como trabajadores migrantes indocumentados.

En la casa estábamos bien, ellos (sus padres) trabajaban, ganaban bien y sí ganaban bien para comer, para tener una casa y sí vivíamos bien, pero ellos querían que yo siguiera estudiando allá (en Estados Unidos). Y mi papa me dijo: te voy a mandar allá para que estudies, tu tía te va a cuidar, y me mandó y me dijo que mi tía me iba a recoger, es que no teníamos lo suficiente para tener estudios (Gloria).

La excepción parece ser el caso de Carolina, quien aparentemente migró ante el hecho de que en Chiapas su padre entabló una nueva relación conyugal y porque ella misma decidió reunificarse con su 
madre y hermanos en la ciudad de Nueva York, quienes se quedaron allá después de la deportación de su padre. Sin embargo, su relato también deja entrever arreglos y decisiones familiares.

Hace un año que me fui con ellos (a vivir con sus abuelos). Allá (en Estados Unidos) mi mamá estaba con mi papá, pero allá se separaron, si y este luego a mi papá lo deportaron y lo detuvieron meses en migración. Y luego este, yo pues vivía sola en una casa con una señora que llegaba a cuidar a mi sobrino y de allí pues cuando llegó él (a Oaxaca) pues vivía con él, y después él se, bueno buscó a otra mujer, de allí la llevó a vivir y yo me salí (Carolina).

Su caso es un ejemplo de la migración de familias mexicanas completas a los Estados Unidos, pero también de cómo "la vivencia en un entorno cultural distinto pueden provocar cambios", aunque en algunos casos estos son "procesos lentos y ambivalentes, cargados de conflictividad, que pueden experimentar retrocesos en situaciones particulares" (Ariza y de Oliveira, 2001:22-23). Más allá de lo anterior, los relatos de Gloria y Carolina muestran, por un lado, que las niñas migrantes provienen de diferentes tipos de familias, pero sobre todo, las formas y expectativas de crianza transnacional en las que participan diferentes actores sociales de distintas maneras (Mummert, 2011:103-104); y por otro, que la migración de niñas mexicanas puede ser por motivos educativos o de reunificación familiar.

\section{Niñas y redes sociales de apoyo migratorio}

No obstante, ni una ni otra cosa es posible sin la existencia de redes sociales migratorias. Como perspectiva teórica, ésta alude a los lazos que vinculan comunidades transnacionales, que unen a migrantes y familiares a través de diversas relaciones sociales (Massey et al., 1991), y en los casos presentados prueba de ello son los nexos de las menores con familiares ya residentes en Estados Unidos.

De ahí de Houston nos iban a pasar a New York, mi papá me dio dinero, y pues no pudimos pasar. Nos iba a recoger un tío por parte de mi papá. No sentí nada al viajar... bueno nomás porque iba a dejar a mi papá y mi mamá, me sentí mal porque iba a dejar a mis papás, a mis tíos, pero era para ayudar a mis papás. Yo iba allá a estudiar en el colegio, a vivir con una tía de allá y a trabajar allá, por eso me quise ir y también mis papás (Gloria).

Y pues de eso yo le dije, se iban a venir unos de allí de mi pueblo, se iban a venir para acá (Estados Unidos) y yo le dije a mi mamá pues que yo me quería ir, porque la quería ver a ella. Le hablé y ya me dijo que si mi papá estaba de acuerdo, y pues yo le dije que yo a él no le iba a preguntar porque él ya estaba aparte, y pues, y él nada más dijo que sí, que si yo me quería ir, pero que lo pensara bien porque no era fácil, y de allí pues me vine, mi mamá me consiguió dinero y todo, me vine pues (Carolina).

Sin duda, la prestación monetaria, el alojamiento o los alimentos forman parte de los mecanismos de apoyo de parte de las redes sociales de migrantes indocumentados en Estados Unidos hacia sus familiares en México (Rubio Salas, 2001). No obstante, también es necesario reconocer que los mecanismos de apoyo de las redes inician desde el lugar de origen de las o los migrantes. Al respecto, los relatos de las niñas migrantes evidencian que si bien mecanismos de apoyo como los descritos estaban garantizados por sus familiares y parientes en "el otro lado", en el lado mexicano también contaron con el apoyo de tías, primos o un cuñado, quienes tenían alguna experiencia migratoria previa para iniciar el viaje hacia la frontera norte.

Sin embargo, al igual que en el caso de innumerables adultos migrantes mexicanos, los relatos de Gloria y Carolina también muestran otro actor central dentro de las redes sociales migratorias: el coyote. Claramente, este actor forma parte de lo que Spener (2007: 119) denomina coyotaje, a decir de "un sistema de estrategias y prácticas de migración laboral conducidas por coyotes".

Mis papás no me dieron dinero para venirme, ellos arreglaron el señor que me iba a traer. Sí, o sea me iba a venir con mi cuñado, pero ahí nos guiaba un señor, el que nos iba a cruzar por McAllen. No sé cómo sería, porque nos dijeron: tú sigues a este señor que va a cruzar el río, sigan a este señor. Y luego de ahí nos iba a llevar con mi tío a New York y después con mi tía en Chicago. Mi cuñado no conocía muy bien a este señor, porque mis papás hicieron el acuerdo con él. Lo conocían, yo sólo lo vi una vez, pero no sé si vivirá ahí en mi pueblo (de Chiapas) (Gloria). 
En esta (vez que cruzaron) pues primero fuimos a... por Reynosa cruzamos el río y luego caminamos en el desierto. Allí no pagamos al coyote, bueno, allí solamente le dimos 5,000 pesos, en Reynosa, ya los 5,000 dólares se los dimos cuando ya estábamos en Texas. A esta persona nos la recomendaron, era un hombre, este... un primo que yo tenía y varios ya habían cruzado con el señor y sí pasaron (Carolina).

Como se dijo antes, Spener (2007) hace referencia al coyote y al coyotaje con relación al cruce clandestino de migrantes adultos que buscan un empleo, pero al menos en los casos de menores migrantes como las descritas, este actor y sistema no persiguen el mismo fin, pues se trata de la conducción de niñas acompañadas cuyos objetivos no son propiamente laborales en los Estados Unidos.

Pero por otro lado, a pesar de que medió un pago, en ambos casos estos actores fueron "contratados" en requerimiento de los miembros de la familia de origen de las niñas migrantes y en complicidad con ellas, pues prevalecía una relación social entre unos y otros, lo que propició no sólo echar mano de una red, sino también depositar la confianza en ellos para el viaje migratorio. Sin duda, las redes sociales migratorias involucran a una diversidad de sujetos en ambos lados de la frontera, y los relatos de Gloria y Carolina ejemplifican las formas en que operan dichas redes a pesar de las distancias, el aumento de la seguridad fronteriza en los Estados Unidos, el incremento de la violencia en el norte de México y los riesgos para los menores migrantes (Hernández, 2012).

\section{Niñas y viaje a la frontera norte de México}

A lo largo de los relatos es posible identificar que para las niñas migrantes cruzar de manera indocumentada a los Estados Unidos fue un objetivo que no podían postergar, ya fuera por motivos educativos o de reunificación familiar. Pero como se observa, ello implicó que el viaje a la frontera fuera realizado con base en lo que Sandoval (2012) denomina infraestructuras e itinerarios transfronterizos.

En los relatos de las niñas migrantes las infraestructuras fueron desde autobuses hasta aviones que tomaron en sus lugares de origen para llegar a la frontera norte de México; así como vehículos particulares al cruzar el río Bravo, acompañadas de sus familiares, parientes y un coyote. Éstas permitieron seguir un itinerario migratorio tanto dentro del país como al pasar la frontera.

Cuando salimos a mí (sus papás) me dieron 200 pesos. De Chiapas a México nos venimos en autobús. Llegamos a México, del aeropuerto de México cogimos un avión para llegar acá en Reynosa. De ahí en Reynosa nos cogió un señor y de ahí nos pasó de ahí, nos iba a pasar a McAllen. El autobús y el avión no lo pagó mi cuñado, eso ya estaba bien, esos señores ya sabían. Bueno, yo no sé por qué ellos nos decían, nos deban (el) boleto de avión. Sí, un señor nos daba (el) boleto de avión, ese día lo compraron. O no sé quién los compraría pero nos venimos acá (Gloria).

Me fui con mi tía, mi cuñado y este, otros primos. Y (sus abuelos) no dijeron nada, qué iban a decir, sí se preocuparon pues porque dicen: quizás pasas, pues ya está bien que pasaste, pero si te agarran pues, ya allí está la cosa. Nos venimos en autobús desde allá (Oaxaca) hasta acá en Reynosa, cruzamos el río y luego caminamos por el desierto, luego ya nos esperaban unas camionetas en el "levantón", pero después caminamos más hasta llegar a una casa, y caminamos y nos agarró la migra en la mañana (Carolina).

El viaje migratorio, sin embargo, no sólo se articuló con infraestructuras e itinerarios para la movilidad en un espacio geográfico y social, sino también con lo que López-Pozos (2009) ha llamado "el costo emocional" entre los niños migrantes: a decir la alteridad y el sufrimiento de los menores al emprender un viaje migratorio, o bien (intentar) vivir en dos culturas diferentes.

\section{Niñas y emociones en el viaje migratorio}

Aunque las emociones entre migrantes son un tema sumamente subjetivo y poco estudiado (De la Torre, 2010), aquellas experimentadas por las niñas migrantes constituyen una dimensión que permite captar los 
significados que ellas construyen en su experiencia migratoria. En los relatos presentados, sobresalen al menos cuatro emociones: la felicidad, el miedo, la sorpresa y la tristeza.

Por supuesto, las niñas migrantes no necesariamente tuvieron las emociones en ese orden, pues en diferentes momentos del viaje migratorio ellas las experimentaron con relación a otras personas y situaciones. La felicidad, por ejemplo, la experimentaron de cierta forma al sentir el apoyo moral de sus padres para iniciar el viaje, pero también al construir una imagen de lo que sería su vida en los Estados Unidos, al menos así lo expresó Gloria en su relato.

Mi papá era el que me decía que me fuera (a Estados Unidos) para que estudiara. Mi mamá me dijo que si yo quiero irme, que ella también me va ayudar pero que si no quiero irme no hay ningún problema, yo le dije que sí me quiero ir y por eso me mandaron. Me nadaron a mí nomás, y con mi cuñado, porque mi hermana ya estaba embarazada, tiene dos meses, sí, iba a cumplir tres, yo creo que cumplió tres. Y me fui por eso, para estudiar y para luego ayudar a mis papás (Gloria).

Al mismo tiempo sintieron el miedo, particularmente al encontrarse en pleno viaje migratorio y vivir una serie de riesgos tanto antes como después de cruzar la frontera. A pesar de viajar acompañadas con familiares o parientes, la incertidumbre de lograr o no su meta incrementó su temor, en especial por ser su primera vez como migrantes:

Cuando íbamos a cruzar el río pensé que de ahí todo iba a ser fácil, que no iba a ver nadie ahí y pues estaba migración y nos cogieron. Poco (miedo me dio) porque dijeron a mí y a mi cuñado y les pregunté: si nos agarran, ¿a dónde nos llevan? Y dijo que nos iban a llevar a la cárcel, por eso me daba miedo (Gloria).

Bueno, cruzamos carreteras y este, y también cruzamos una carretera, donde está junto con una vía, unas vías de tren, y después este... íbamos a recoger agua... y en una ocasión nos quedamos a dormir en una casa, pero no había gente, no había nadie, estaba sola la casa y nos quedamos a dormir allí. Y nosotros teníamos miedo porque, este, quizás podría llegar el dueño de la casa y nos encontrará allí (Carolina).

De forma paralela al miedo se gestó la sorpresa, emoción que brotó al ser encontradas y detenidas por los agentes de la Patrulla Fronteriza. Pero por otro lado, la sorpresa no sólo se dio al vivir un evento inesperado como el antes descrito, sino también al momento de reflexionar para sí por qué el plan de cruzar la frontera sin ser detenidas no resultó.

Y finalmente se tiene la tristeza, emoción referente al desaliento o el desánimo de las niñas al no haber logrado su meta de cruzar sin ser detenidas. Ésta se mescló con el miedo, pero también emergió al sentir aflicción por su familia. Ya sea que ésta se encuentre de lado mexicano o americano, entran en un estado de frustración pues tanto su proyecto personal como familiar, fallaron.

Pero a nosotros sí nos dijeron que estaba duro (cruzar), pero nosotros dijimos, que me han dicho mis primos, mis primos están allá, decían que estaba duro, que está duro. Yo les dije: ¿por qué a nosotros nos hacen esto? Yo imaginaba Estados Unidos un bonito el lugar, estar con mi tía, con mis primos, bonito estar allá pero al mismo tiempo feo porque estaba dejando a mis papás (Gloria).

Mi tía, el que iba manejando y yo, íbamos y fuimos a donde tenía que cobrar mi tía, de allí fuimos a una tienda y pues compramos ropa, de allí nos regresamos, íbamos en la carretera cuando nos empezó a seguir la policía, y de allí pues nos detuvieron. A mí me dieron ganas de llorar, porque después de todo lo que pasamos, ya en el otro lado, y nos agarran, aunque luego pensé: ¿y si nos llevan a la cárcel?, pero mi tía dijo no, estaremos bien, pero no sé, me dio cosa no lograrlo (Carolina).

Sin duda, el tema de las emociones durante el viaje migratorio de niñas mexicanas, abre un campo poco explorado y relacionado con la construcción social de significados en un fenómeno histórico y sociocultural como es la migración indocumentada. Pero por otro lado, el tema también nos permite deducir que al menos entre menores de edad la experiencia migratoria vincula tanto procesos estructurales como subjetivos. Quizás un buen ejemplo de ello es la última dimensión que sobresale en los relatos de Gloria y Carolina: la referente a su detención en los Estados Unidos. En esta fase, como ya se 
dijo, las menores experimentaron diferentes emociones, pero también reconocen "el riesgo" de ser detenidas en tanto un procedimiento institucional y latente en los Estados Unidos.

Sin embargo, las narrativas sobre esta dimensión también dejan entrever cómo el procedimiento de detención a veces implica la violación de derechos humanos de los migrantes menores de edad, tal como lo enfatizan las niñas en sus relatos y como lo han denunciado activistas que están en contra de la detención de niños migrantes (Gómez Medina, 2012).

Cuando nos agarraron (tuvo miedo). Nos cogieron y nos dijeron así a la fuerza y nos empujaron y entonces de ahí me dio miedo, entonces yo quería estar con mi cuñado, pero me dijeron que ahí no podía entrar ustedes, son mujeres, a él lo llevaron en otro carro y a mí en otro carro, por eso tenía miedo pero yo tenía miedo de que nos llevaran y nos iban a separar (Gloria).

Y pues nos llevaron, a un lugar donde trabajan y de allí nos mandaron para acá. Nos preguntaron que por qué habíamos cruzado, que nosotros no tenemos derechos, eso fue lo que nos dijeron, y nos hicieron preguntas, que de dónde éramos, cuántos años teníamos y este nos tomaron fotos y las huellas, sí, todos los dedos y (fotos) de la cara nomás. Pues yo, lo único que hice fue empezar a llorar, tanto esfuerzo, tantos días que pasé en el desierto como para que me fuera a pasar eso (Carolina).

Ser empujadas contra las camionetas, separadas de sus familiares o parientes, dejarles creer que irán a la cárcel, e incluso ser interrogadas y detenidas por varias horas, son sólo algunos de los indicios de cómo vivieron la detención las niñas migrantes y cómo, posiblemente, viven esta fase otros menores migrantes mexicanos que cruzan la frontera solos o acompañados. En suma, los relatos muestran las estrategias tanto personales como colectivas que usan las menores migrantes para cruzar la frontera, así como su posición de vulnerabilidad en este proceso (Aquino Moreschi, 2012); pero sobre todo, introducen en su propia "construcción social de la realidad" (Berger y Luckmann, 2006) al narrar y elaborar significados en torno a un proceso vivido.

\section{Conclusiones}

A pesar de que la migración indocumentada de menores mexicanos a los Estados Unidos es un fenómeno histórico (Hernández Sánchez, 2008), sólo hasta recientemente ha sido considerada como un tema de interés para los estudiosos del país (Mancillas Bazán, 2009), pues antaño se pensaba que era más relevante el análisis de la migración de adultos por las rutas y riesgos vividos hasta la frontera norte, y las remesas enviadas a sus lugares de origen.

Recientemente, las líneas que se han abordado van desde la exploración del procedimiento institucional que se sigue en el caso de los llamados niños, niñas y adolescentes migrantes (Gallo Campos, 2004), los sistemas y violación de los derechos humanos de la niñez migrante (Ramírez Romero, et. al., 2009 y Paris Pombo, 2010), hasta mapeos del proceso migratorio que viven menores tanto mexicanos como centroamericanos (Chávez y Menjívar, 2009). Sin embargo, como ha afirmado Hondagneu-Sotelo (2011:227) en una revisión de estudios sobre "migración infantil", éstos son incipientes y mucho menos aquellos que hayan analizado las dinámicas de género tanto de "los niños que se quedan" en México como de los que emprenden el viaje migratorio o de los que trabajan en los Estados Unidos. Por ello, son necesarias investigaciones que indaguen este tema haciendo diferenciaciones culturales.

Claramente, aunque reducidos, los estudios sobre la materia han hecho aportaciones relevantes. No obstante, la migración indocumentada de menores mexicanos ha sido vista como un fenómeno, además de insignificante, homogéneo sin distinciones por género o edad. En parte, ello se debe al hecho de que, al igual que en la migración transnacional de adultos mexicanos, en la de menores predominan más los niños que las niñas, en especial no acompañados. El estudio de las experiencias de algunas niñas migrantes mexicanas, repatriadas de los Estados Unidos, además de una riqueza metodológica al usar el relato de vida como técnica (Bertaux, 2005), también contribuye al conocimiento de sus experiencias como actores sociales que producen significados (Ariza y Velasco, 2012), a la vez que están inmersas en un proceso estructural caracterizado por crisis socioeconómicas y políticas en México que orillan a migrar a las menores. 
Una de las aportaciones de la presente pesquisa refiere que las migraciones internacionales no sólo hacen más complejos los arreglos y relaciones entre las familias de los adultos migrantes (Ariza y Oliveira, 2001), sino también que tienen un impacto entre los hijos e hijas de éstos al forjarse reacomodos internos que pueden resultar en la formación de familias transnacionales. Por supuesto, ello en parte se debe a las relaciones tanto familiares como de género que se tejen entre familias del México rural con larga tradición migratoria a los Estados Unidos y que, derivado de ello, negocian la crianza y educación de los hijos en ambos lados de la frontera (Mummert, 2011). No obstante, como lo muestran los casos presentados, la incursión de niñas en la migración indocumentada es un fenómeno relativamente nuevo y de riesgo para ellas.

Desde una perspectiva de género, la migración de niñas mexicanas a los Estados Unidos rompe con el paradigma referente a que sólo lo hacían los varones -inicialmente adultos y posteriormente menores de edad- en tanto apropiaban un referente de masculinidad que culturalmente los fuerza a seguir con un modelo de ser los proveedores, quienes trabajan y, sobre todo, demostrar que son ellos quienes tienen el valor de enfrentar peligros (Olavarría, 2001).

Si bien se trata del análisis de sólo dos casos o relatos migratorios de niñas, estos también ponen en evidencia que además de referirse a un fenómeno reciente, que evidencia una nueva corriente migratoria del sur de México a los Estados Unidos (Ávila Sánchez, 2007), confronta las motivaciones para migrar antaño supuestamente propias de los varones (Keijzer de y Rodríguez, 2007 y Rosas, 2007) al evidenciar interés no sólo en la reunificación familiar, sino también en la educación y el trabajo para apoyar económicamente a la familia de origen.

Más allá de lo anterior, los resultados también ponen en evidencia las formas en que la migración indocumentada de niñas mexicanas es posible a razón de redes sociales migratorias (Massey, et al., 1991), especialmente aquellas tejidas por sus familiares tanto de uno como de otro lado de la frontera; pero sobre todo, la manera en que llegan a formar parte del sistema de "coyotaje" que predomina en México (Spener, 2007) al hacer uso de estos actores clandestinos.

A pesar de que recientemente un estudio regional (Vargas Orozco, et al., 2012) evidenció que, la vulnerabilidad de las menores migrantes por el sólo hecho de ser niñas, las coloca en una situación de riesgo mayor al hacer uso de "coyotes" para cruzar la frontera, en los relatos de las entrevistadas se pone a debate esta situación, en especial porque los "coyotes" son actores que previamente han construido una relación íntima con sus familias al ser contratados o tener algún parentesco. No obstante, el viaje migratorio a la frontera norte de México, al menos en años recientes por la región noreste del país, se ha vuelto más riesgoso ante la violencia contra cientos de migrantes adultos que han usado esta ruta y que han sido secuestrados e incluso asesinados por grupos del crimen organizado (Izcara-Palacios, 2012), lo que pone en perspectiva la fragilidad de los menores, en especial de las niñas.

En parte, la vulnerabilidad de éstas durante el proceso migratorio queda manifiesto en una dimensión no explorada en los estudios que abordan el tema (De la Torre, 2010): las emociones construidas y vividas por las y los menores antes y después de cruzar la frontera entre México y Estados Unidos. El estudio llevado a cabo mostró cómo las niñas experimentaron algunas de éstas a lo largo del viaje, pero en especial al cruzar el río Bravo y ser detenidas por agentes de la Border Patrol.

Pero ya sea que se trate del análisis de la estructura familiar de las menores migrantes, de sus motivaciones, redes sociales, el itinerario migratorio o las emociones tejidas en el viaje, tales dimensiones sólo dan un panorama de cómo al vivir la experiencia migratoria las menores refuerzan sus identidades de género y moldean sus subjetividades como parte del proceso. Sin embargo, también es necesario considerar que estudios de caso como los presentados deben debatir escenarios estructurales relacionados con reformas migratorias transnacionales, no sólo en los Estados Unidos donde la Cámara de Representantes aún no aprueba la propuesta del Presidente Barack Obama de legalizar a millones de inmigrantes (El Tiempo, 2013), sino también en México donde recientemente la Cámara de Diputados aprobó una reforma a la Ley de Migración enfocada a la protección de los derechos de la niñez migrante (CNN México, 2013). Es decir, la migración de menores mexicanos en general, y la de niñas en particular, pone al descubierto cómo esta experiencia forma parte de un proceso subjetivo a la vez que estructural (Aquino Moreschi, 2012), lo que demanda enfoques teóricos y metodológicos relacionales para profundizar en este tema tanto en México como en otras regiones donde cada vez más niños y niñas se suman a los flujos migratorios transnacionales de manera indocumentada. 


\section{Referencias bibliográficas}

Alvarado Juárez, A. M. (2008): "Migración y pobreza en Oaxaca", El Cotidiano, 23 (148): 85-94.

Aquino Moreschi, A. (2012): "Cruzando la frontera: experiencias desde los márgenes", Frontera Norte, 24 (7): 7-34

Aresti de la Torre, L. coord. (2010): Mujer y migración. Los costos emocionales. México: Universidad Autónoma de Nuevo León-Universidad Autónoma Metropolitana-Universidad Michoacana de San Nicolás de Hidalgo.

Ariza, M. y De Oliveira, O. (2001): "Familias en transición y marcos conceptuales en redefinición", Papeles de Población, 28: 9-39.

Ariza, M. y Velasco, L. coords. (2012): Métodos cualitativos y su aplicación empírica. Por los caminos de la investigación sobre migración internacional. México: Universidad Nacional Autónoma de México/Instituto de Investigaciones Sociales-El Colegio de la Frontera Norte.

Berger, P. y Luckmann, Th. (2006): La construcción social de la realidad. Buenos Aires: Amorrortu.

Bertaux, D. (2001): "Los relatos de vida en el análisis social", en Aceves, J. Comp.: Historia oral. México: Instituto Mora.

- (2005): Los relatos de vida. Perspectiva etnosociológica. Barcelona: Edicions Bellaterra.

CAMEF (2012): "Estadísticas de menores migrantes ingresados". Matamoros, México: Documento interno del Centro de Atención al Menor Fronterizo.

Centro de Estudios Migratorios (2010): "5.4 Eventos de repatriación de menores mexicanos desde Estados Unidos, según grupos de edad, condición de viaje y sexo, 2010", Boletín Mensual de Estadísticas Migratorias. V. Repatriación de Mexicanos de EUA. México: Instituto Nacional de Migración.

- (2011): "5.4 Eventos de repatriación de menores mexicanos desde Estados Unidos, según grupos de edad, condición de viaje y sexo, 2011", Boletín Mensual de Estadísticas Migratorias. V. Repatriación de Mexicanos de EUA. México: Instituto Nacional de Migración.

- (2012): "5.4 Eventos de repatriación de menores mexicanos desde Estados Unidos, según grupos de edad, condición de viaje y sexo, 2012". Boletín Mensual de Estadísticas Migratorias. V. Repatriación de Mexicanos de EUA. México: Instituto Nacional de Migración.

CNN México (2013): "La Cámara de Diputados aprueba más protección para menores migrantes". Disponible en web: http://origin.www.cnnmexico.com/nacional/2013/03/21/la-camara-de-diputadosaprueba-mas-proteccion-para-menores-migrantes

Chavez, L. y Menjivar, C. (2010): "Children without Borders: A Mapping of the Literature on Unaccompanied Migrant Children to the United States", Migraciones Internacionales, 5 (3): 71-111.

Durand, J. coord. (1996): El norte es como el mar. Entrevistas a trabajadores migrantes en Estados Unidos. Guadalajara: Universidad de Guadalajara-Centro Universitario de Ciencias Sociales y Humanidades.

El Tiempo (2013): "Obama pide a Cámara de Representantes aprobar reforma migratoria". Disponible en web: http://www.eltiempo.com/mundo/estados-unidos/ARTICULO-WEB-NEW_NOTA_INTERIOR12927702.html

Estrada Inda, L. (2007): El ciclo vital de la familia. México: Debolsillo.

Gallo Campos, K. (2004): Niñez migrante en la frontera norte. Legislación y procesos. México: DIF NacionalUNICEF México.

Glendhill, J. (2009): "El reto de la globalización: reconstrucción de identidades, formas de vida transnacionales y las ciencias sociales", en Mummert, G. ed.: Fronteras fragmentadas. Zamora: El Colegio de Michoacán-Centro de Investigación y Desarrollo del Estado de Michoacán.

Gómez Medina, C. (2012): "Activistas lanzan campaña contra la detención de niños migrantes", La Jornada, 8 de noviembre: 19.

Hernández Sánchez, M. E. (2008): Niños deportados en la frontera de Ciudad Juárez. México: Instituto Nacional de Antropología e Historia.

Hernández, O. M. (2012): "Los chavos migrantes, riesgos y masculinidad", en Milenio. Disponible en web: http://www.milenio.com/cdb/doc/impreso/9144612

Izcara-Palacios, S. P. (2012): "Violencia contra inmigrantes en Tamaulipas", European Review of Latin American and Caribbean Studies, 93: 3-24.

Jauregui Díaz, J. A. y Ávila Sánchez, M. de J. (2007): "Estados Unidos, lugar de destino para los migrantes chiapanecos", Migraciones Internacionales, 4 (1): 5-38. 
Keijzer De, B. y Rodríguez, g. (2007): "Hombres rurales: nueva generación en un mundo cambiante", en Amuchástegui, A. y Szasz, I. coords.: Sucede que me canso de ser hombre... Relatos y reflexiones sobre hombres y masculinidades en México. México: El Colegio de México.

López-Pozos, C. (2009): "El costo emocional de la separación en niños migrantes: un estudio de caso de migración familiar entre Tlaxcala y California", Agricultura, Sociedad y Desarrollo, 6 (1): 81-103.

Mancillas Bazán, C. (2009): "Migración de menores mexicanos a Estados Unidos", en Leite, P. y Giorguli, S. eds.: El estado de la migración. Las políticas públicas ante los retos de la migración mexicana a Estados Unidos. México: Consejo Nacional de Población.

Massey, D. S. et al. (1991): Los ausentes. El proceso social de la migración internacional en el occidente de México. México: Consejo Nacional para la Cultura y las Artes.

Medina Núñez, I. (1996): "México: crisis económica y migración", Espiral, III (7): 129-141.

Mummert, G. (2011): "Todo queda en familia (transnacional): niños mexicanos a cargo de cuidadores alternativos", en Lestage, F. y Olavarría, M. E. coords.: Parentescos en un mundo desigual. Adopciones, lazos y abandonos en México y Colombia. México: Universidad Autónoma Metropolitana IztapalapaMiguel Ángel Porrúa.

Olavarría, J. (2001): "Invisibilidad y poder. Varones de Santiago de Chile", en Viveros, M., Olavarría, J. y Fuller, N.: Hombres e identidades de género. Investigaciones desde América Latina, Bogotá: Universidad Nacional de Colombia.

París Pombo, M. (2010): Procesos de repatriación. Experiencias de las personas devueltas a México por las autoridades estadounidenses. México: Woodrow Wilson Internationl Center for Scholars Mexico Institute-El Colegio de la Frontera Norte. [Documento de trabajo]

Quintero Ramírez, C. (2007): El Programa Interinstitucional de Atención a Menores Fronterizos. El caso del Programa de Menores Migrantes o Repatriados en Matamoros, Tamaulipas. Matamoros: El Colegio de la Frontera Norte. [Reporte de investigación]

- (2011): "Migración en Matamoros: del esplendor económico a la recesión económica", en Cruz Piñeriro, R. y Quintero Ramírez, C. coords.: Ires y venires. Movimientos migratorios en la frontera norte de México. México: El Colegio de la Frontera Norte-El Colegio de San Luis.

Ramírez Romero, S. et al. (2009): Más allá de la frontera, la niñez migrante: son las niñas y niños de todos. Estudio exploratorio sobre la protección de la niñez migrante repatriada en la frontera norte. México: Secretaría de Desarrollo Social-Instituto Nacional de Desarrollo Social-Caminos Posibles S. C.

Randall, M. (1992): "¿Qué es y cómo se hace un testimonio?", Revista de Crítica Literaria Latinoamericana, XVIII (36): 221-245.

Rojas, O. (2008): Paternidad y vida familiar en la ciudad de México. México: El Colegio de México.

Rosas, C. (2007): "El desafío de ser hombre y no migrar. Estudio de caso en una comunidad de Veracruz", en Amuchástegui, A. y Szasz, I. coords.: Sucede que me canso de ser hombre... Relatos y reflexiones sobre hombres y masculinidades en México. México: El Colegio de México.

Rubio Salas, R. (2001): "Redes sociales y mecanismos de apoyo en la migración de mexicanos a Estados Unidos: datos de una encuesta de flujos". Ponencia presentada en el VI Congreso de la Asociación de Demografía Histórica, Castelo Branco, Brasil, 18-20 de abril.

Sánchez Munguía, V. (1993): "Matamoros-Sur de Texas: el tránsito de los migrantes de América Central por la frontera México-Estados Unidos", Estudios Sociológicos, XI (31): 183-207.

Sandovál, E. (2012): Infraestructuras transfronterizas. Etnografía de itinerarios en el espacio social Monterrey-San Antonio, México: Centro de Investigaciones y Estudios Superiores en Antropología Social-El Colegio de la Frontera Norte.

Silva Quiroz, Y. (2010): "Niñez migrante retornada: migración en un contexto de riesgos (Nogales, Tijuana y Cd. Juárez)". Tijuana: El Colegio de la Frontera Norte. [Tesis de Maestría en Demografía]

Spener, D. (2007): "Cruces clandestinos: migrantes, coyotes y capital social en la frontera noreste de México-sur de Texas", en Arzaluz Solano, S. coord.: La migración a Estados Unidos y la frontera noreste de México. México: El Colegio de la Frontera Norte-Miguel Ángel Porrúa.

Valdés Gardea, G. coord. (2008): Achicando futuros. Actores y lugares de la migración. México: El Colegio de Sonora.

- (2011): La antropología de la migración. Niños y jóvenes migrantes en la migración. México: El Colegio de Sonora. 
Vargas Orozco, M. et al. (2012): "Menores migrantes repatriados no acompañados en Reynosa, Tamaulipas: un análisis descriptivo del flujo migratorio", CienciaUAT, 23 (1): 6-13.

\section{Breve CV del autor}

Oscar Misael Hernández Hernández es Doctor en antropología social por El Colegio de Michoacán y Graduado en sociología por la Universidad Autónoma de Tamaulipas. Actualmente es investigador titular en El Colegio de la Frontera Norte, sede Matamoros, así como miembro del Sistema Nacional de Investigadores en México. Es coordinador del libro Migrantes allá y acá: mujeres y hombres en Estados Unidos y el noreste de México (2014) y coautor de Migración y repatriación de menores por la frontera Tamaulipas-Texas (2015). Su principal línea de investigación es la migración irregular de menores mexicanos por la frontera México-Estados Unidos. 